\title{
MONITORING AIR QUALITY FROM SPACE \\ The Case for the Geostationary Platform
}

by W. A. Lahoz, V.-H. Peuch, J. Orphal, J.-L. Attié, K. Chance, X. Liu, D. Edwards, H. Elbern, J.-M. Flaud, M. Claeyman, and L. El Amraoui

A geostationary multispectral sensor provides the high spatiotemporal resolution continental-scale observations of lower-tropospheric pollutants needed to monitor, forecast, and manage air quality on a daily basis.

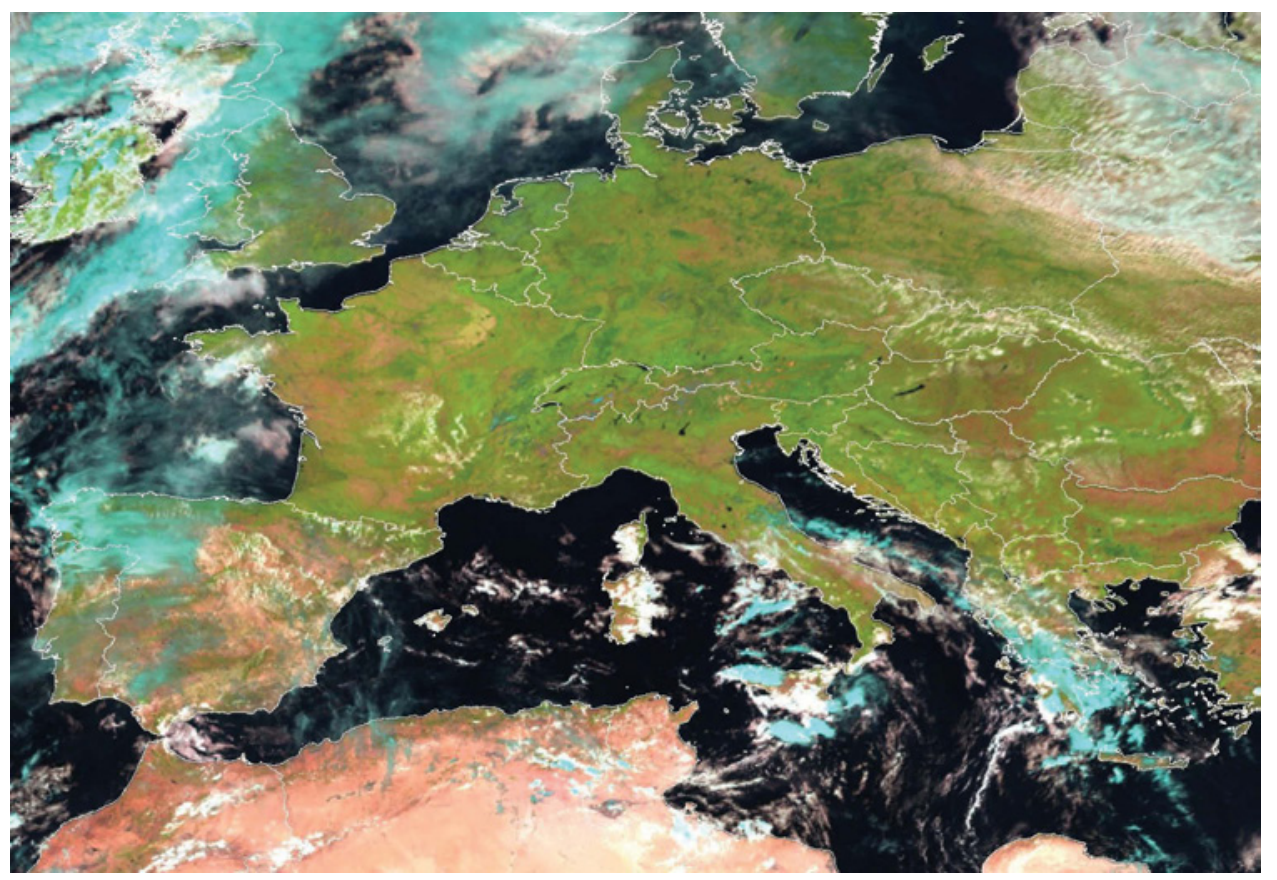

Europe as observed from a geostationary satellite (RGB composition of MSG-SEVIRI data, 22 Sep 2010): red and green show land and vegetation, respectively, while white and blue show thick and cold clouds, respectively. (Courtesy of F. Olesen, KIT)

A fundamental challenge for humankind at the start of the twenty-first century is to respond in the most efficient way to global changes, which put increasing pressure on ecosystems, the economy, and human society. This challenge has the following three key interlinked aspects: 1) global change in the Earth system, 2) ecosystem degradation and its impact on the sustainability of human society, and 3) growing human demand on resources and associated societal vulnerability. Atmospheric composition is a key parameter, both contributing to processes associated with global change and reflecting the outcome of these processes.

AQ (see the appendix) is defined by the atmospheric composition of gases and particulates near the Earth's surface. This composition depends on local 
contributions (emissions of pollutants), chemistry, and transport processes; it is highly variable in space and time (McNair et al. 1996). Key lower-tropospheric pollutants include $\mathrm{O}_{3}$, aerosols (e.g., $\mathrm{PM}$ ), and the $\mathrm{O}_{3}$ precursors $\mathrm{NO}_{x}\left(=\mathrm{NO}+\mathrm{NO}_{2}\right)$ and VOCs (Brasseur et al. 2003). Tropospheric $\mathrm{O}_{3}$ controls the oxidation of many tropospheric species through reactions involving the $\mathrm{OH}$ (Brasseur et al. 2003). Owing to its relatively longer lifetime (in comparison with other easily observed species), tropospheric CO observations provide information on sources of pollution and transport processes affecting $\mathrm{AQ} \cdot \mathrm{C}_{2} \mathrm{H}_{2} \mathrm{O}_{2}$ is virtually unaffected by road traffic emissions and thus is a good indicator of photochemical smog (Volkamer et al. 2005).

Air quality impacts human society: high concentrations of $\mathrm{O}_{3}, \mathrm{PM}$, and $\mathrm{NO}_{2}$ near the Earth's surface cause health problems, in particular, pulmonary and cardiovascular diseases (Brunekreef and Holgate 2002), and recognition is growing of the combined health effects of multiple pollutants (Dominici et al. 2010). Tropospheric CO is not regarded as a health concern outdoors; however, recent work shows a possible link between exposure to urban $\mathrm{CO}$ concentrations and cardiac problems in rats (Lucas et al. 2010; Meyer et al. 2010). Reduction of life expectancy in the EU as a consequence of $\mathrm{PM}_{2.5}$ pollution has been estimated to be up to 36 months in heavily polluted regions (e.g., Benelux and the Po Valley; see Deutsche Umwelthilfe 2005). Studies in the United States provide evidence that a reduction of $\mathrm{PM}_{2.5} \mathrm{can}$ increase life expectancy (Pope et al. 2009). Reduction of exposure to ozone and PM pollution is associated with decreases in mortality and hospital admissions resulting from respiratory and cardiovascular diseases. Weather can alter AQ, for example, during summer heat waves and winter episodes. ${ }^{1}$ Health costs attributable to AQ are significant. ${ }^{2}$

Conventional air pollutant emissions affect climate directly (via $\mathrm{O}_{3}$ and aerosol production) and indirectly via their influence on the oxidizing capacity of the atmosphere and, in particular, the methane lifetime (Solomon et al. 2007). Increasing pollutant emissions (e.g., $\mathrm{CO}$ and $\mathrm{NO}_{\mathrm{x}}$ ) results in increased tropospheric $\mathrm{O}_{3}$ (Crutzen 1974), which is associated with a net positive radiative forcing (Solomon et al.

\footnotetext{
${ }^{1}$ It is estimated the European heat wave of summer 2003 caused a loss of 14,802 lives (mainly elderly) in France (www.grid .unep.ch/product/publication/download/ew_heat_wave.en.pdf). High temperatures increased tropospheric $\mathrm{O}_{3}$ amounts, and anticyclonic conditions ensured their persistence (Vautard et al. 2005). Surface temperature inversions play a major role in AQ, especially during winter when these inversions are strongest. During wintertime cold, calm periods, with a shallow PBL (a few hundred meters above the Earth's surface), PM emissions from road traffic become trapped close to their sources and cannot disperse due to reduced turbulence and mixing with air aloft. Pollution can build up over several days with adverse health effects (www.londonair.org.uk/london).

${ }^{2}$ The cost to the French health system of asthma and cancer incidences directly attributable to AQ has been estimated to be 300-1300 million Euros for 2006 (AFSSET 2007). Estimates of annual health damage (mortality and morbidity) due to air pollution in 2020 for the EU25 countries are estimated to range between 188 billion Euros and 608 billion Euros (see www .cafe-cba.org/assets/baseline_analysis_2000_2020_05-05.pdf). Savings in the EU from complying with WHO guidelines on $\mathrm{PM}_{2.5}$ would total about 31.5 billion Euros annually, including savings on health expenditure, absenteeism, and intangible costs such as well-being, life expectancy, and quality of life (see www.aphekom.org).
}

AFFILIATIONS: LAHOZ-Norsk Institutt for Luftforskning, Norway, and Météo-France, CNRM/GMGEC/CARMA, Toulouse, France; Peuch and El Amraoul-Météo-France, CRNM/GMGEC/CARMA, Toulouse, France; ORPHAL-Karlsruhe Institute of Technology, IMK, Karlsruhe, Germany; AtTIÉ AND CLAEYMAN-Météo-France, CNRM/ GMGEC/CARMA, and Laboratoire d'Aérologie, Université de Toulouse, CNRS/INSU, Toulouse, France; CHANCE AND LIU-HarvardSmithsonian Center for Astrophysics, Cambridge, Massachusetts; EDWARDs - National Center for Atmospheric Research,* Boulder, Colorado; ELBERN-Rhenish Institute for Environmental Research, University of Cologne, Köln, Germany, and Institute of Energy and Climate Research (Troposphere), Forschungszentrum Jülich, Jülich, Germany; FLAUD - Laboratoire Interuniversitaire des Systèmes Atmosphériques, CNRS UMR 7583, Université de Paris-Est, Créteil, France
*The National Center for Atmospheric Research is sponsored by the National Science Foundation. CORRESPONDING AUTHOR: William A. Lahoz, Norsk Institutt for Luftforskning, P.O. Box 100, Instituttveien 18, Kjeller 2027, Norway, and 42 avenue Gaspard Coriolis, Météo-France, CNRM/GMGEC/CARMA, Toulouse 31100, France

E-mail: wal@nilu.no

The abstract for this article can be found in this issue, following the table of contents.

DOI:10.1175/BAMS-D-II-00045.I

In final form 20 July 2011

C2012 American Meteorological Society 
2007). The primary oxidant in the atmosphere of many greenhouse gases, including methane, is $\mathrm{OH}$ (Solomon et al. 2007). Thus, changes in $\mathrm{OH}$ (e.g., resulting from changes in abundances of pollutants such as $\mathrm{O}_{3}, \mathrm{NO}_{\mathrm{x}}$, and $\mathrm{CO}$ ) will directly affect the atmospheric lifetime of these greenhouse gases and, hence, their impact on the climate system.

Climate change in turn may cause significant AQ degradation by changing pollutant dispersion rates, the chemical environment for $\mathrm{O}_{3}$ and aerosol production, and emission strengths [e.g., biosphere, fires, and dust; see Solomon et al. (2007)]. Surface air composition is highly sensitive to $\mathrm{PBL}^{3}$ ventilation, winds, temperature, humidity, and precipitation. Thus, modification of these variables resulting from climate change could affect the concentration and/or lifetime of tropospheric pollutants (e.g., $\mathrm{O}_{3}$ ). The sign and magnitude of these effects are, however, highly uncertain and will vary regionally (Solomon et al. 2007).

Simulations show increases in twenty-first-century tropospheric $\mathrm{O}_{3}$ associated with climate change and increased stratospheric $\mathrm{O}_{3}$ flux into the troposphere (Hegglin and Shepherd 2009; Zeng et al. 2010). An evaluation of the high-emissions IPCC SRES A2 scenario showed global mean surface $\mathrm{O}_{3}$ increases of about 5 ppbv by 2030 and 20 ppbv by 2100 (Prather et al. 2003). More recently, Dentener et al. (2006) confirmed a value of $4.3 \pm 2.2 \mathrm{ppbv}$ for 2030 using an ensemble of global models. These increases are expected to affect human health, ecosystems (Cooper et al. 2010), and climate. Only the introduction of stringent abatement technologies involving international cooperation will keep surface $\mathrm{O}_{3}$ and its impact to acceptable levels (Rypdal et al. 2009).

Throughout the world, decision makers are taking action on emissions abatement to monitor, forecast, and manage AQ. In Europe, for instance, the importance of taking action on AQ and the need for abatement technologies led to the implementation of EU legislation concerning AQ thresholds (Directive 96/62/EC and daughter directives; see http://ec.europa .eu/environment/air/quality/standards.htm), development of a long-term EU strategy for AQ (the CAFE program), and operational services for monitoring and forecasting AQ [e.g., PREV'AIR project in France (Rouil et al. 2009); GEMS and MACC projects in the context of the GMES European program (Hollingsworth et al. 2008)]. In North America, the EPA has set national ambient AQ standards (see www .epa.gov/air/criteria.html). These activities are based on the monitoring of surface concentrations of key pollutants and the scientific understanding of their impact. This requires an understanding of the impact of AQ on human society; that is, health (WHO 2000), ecosystems (WHO 2005), agricultural production and management (Aneja et al. 2008), design and construction of megacities (Molina and Molina 2004), and climate change (Solomon et al. 2007).

Despite implementation of policies in the EU and elsewhere to reduce emissions, AQ issues are likely to remain critical over the next few decades. Benefits should come from enforcing and extending worldwide AQ legislation (Dentener et al. 2006). For $\mathrm{NO}_{\mathrm{x}}, \mathrm{CO}$, and VOCs, industrialized regions show reductions in emissions, while regions dominated by developing countries show significant growth in emissions (Solomon et al. 2007). Observations show trends in tropospheric $\mathrm{O}_{3}$ during the last few decades that vary in sign and magnitude at many locations, but there are indications of significant upward trends at low latitudes (Solomon et al. 2007), as expected from global models (Akimoto 2003). Increasing emissions in China, India, and other developing countries, coupled with transcontinental transport of pollutants, will increase Northern Hemisphere background levels of tropospheric $\mathrm{O}_{3}$ and $\mathrm{PM}_{2.5}$ (Lawrence and Lelieveld 2010).

While emissions that affect pollutants in the troposphere are local, subsequent exchange between the PBL and lowermost free troposphere leads to consequences that are regional and global due to intercontinental transport and the chemical processing that takes place during transport. A pollutant can be transported over regional scales within one day and around the hemisphere within one week; the exchange between hemispheres takes approximately one year in the troposphere. Intercontinental transport thus has a significant impact on the budget of tropospheric pollutants. Simulations from Lin et al. (2010) highlight the important roles of rapid convective transport, orographic forcing, urban photochemistry, and PBL processes in controlling intercontinental transport; these processes may not be well resolved in large-scale AQ models. Difficulty in discriminating between regional and local pollutants fundamentally limits our current understanding of AQ and our ability to quantify AQ and establish what level of AQ is beneficial for human society.

To monitor, forecast, and manage AQ, observations are needed at a high spatiotemporal resolution that is appropriate for capturing variability in the

${ }^{3}$ The PBL extends from the surface to $\sim 1 \mathrm{~km}$ at midlatitudes. 


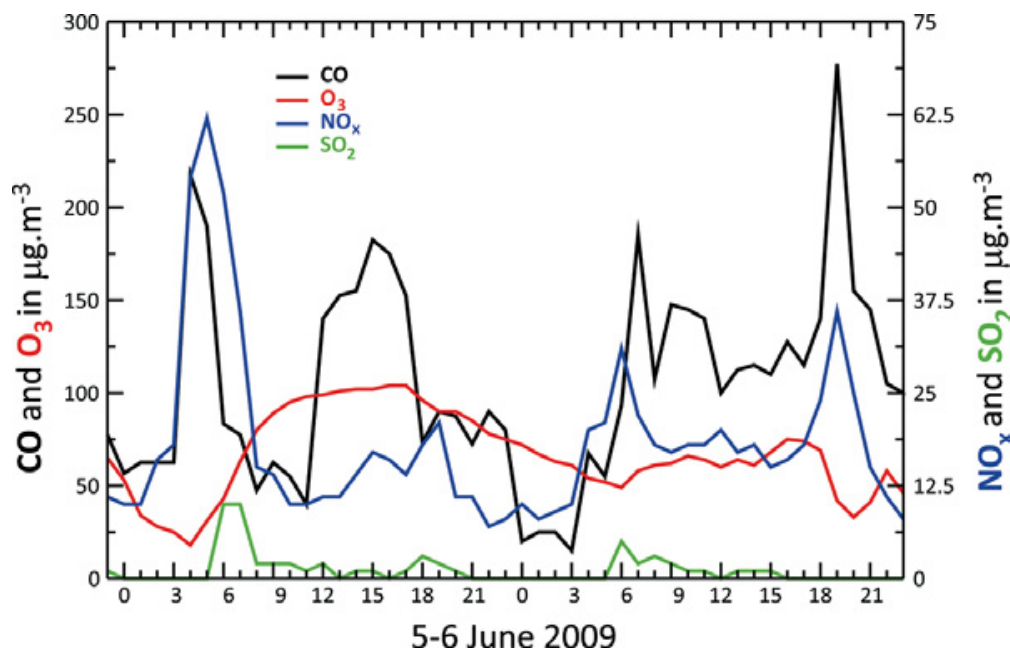

FIG. I. Temporal variability of $\mathrm{O}_{3}$ (red), $\mathrm{CO}$ (black), $\mathrm{NO}$ (blue), and $\mathrm{SO}_{2}$ (green) measured over the period 5-6 Jun 2009 at Reims, France $\left[x\right.$ axis: hour; $y$ axis: concentration $\left.\left(\mu \mathrm{g} \mathrm{m}^{-3}\right)\right]$. This shows highfrequency variability of these species at the ground, where human activity makes AQ an issue. Observations of trace gases and aerosols must be able to capture this temporal variability. Data obtained from BDQA and measurements made and validated by the local network of Reims Atmo-Champagne-Ardenne.

lowermost troposphere (0-3-km height) of either pollutants or their proxies (e.g., HCHO is a proxy for a large number of oxygenated VOCs), including emission sources and sinks, transformation, and transport from urban to intercontinental scales. Appropriate resolutions are 1) temporal frequencies less than $1 \mathrm{~h}$ (see CEOS 2011; Fig. 1), and 2) spatial scales less than $\sim 10 \mathrm{~km}$ (see CEOS 2011; Figs. 2-3). Although local contributions to AQ are well sampled by surface networks (e.g., the EMEP network in Europe), there is a lack of height-resolved regional/ continental-scale spaceborne observations of pollutants in the lowermost troposphere, in particular in the PBL (IGACO 2004).

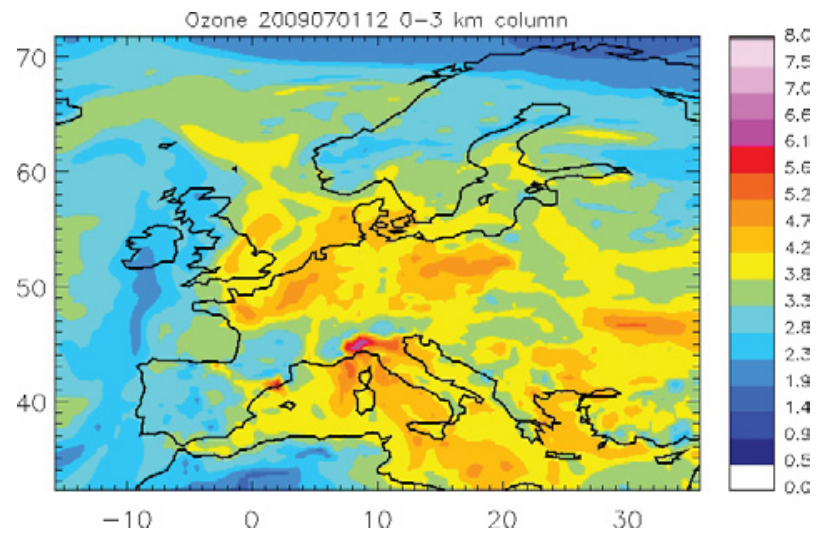

A CASE FOR ADDITIONAL SATELLITE OBSERVATIONS TO MONITOR AIR QUALITY.

The large-scale coverage requirements to monitor AQ indicate the use of satellite platforms. These mostly operate either in geostationary orbit or low Earth orbit. GEO satellites located at $36,000 \mathrm{~km}$ on the equatorial plane orbit Earth with the same angular velocity as the Earth's rotation and, therefore, provide continuous viewing of a selected portion of the Earth (the same location at a constant footprint). LEO satellites in sun-synchronous orbits, the most common for atmospheric measurements, orbit Earth at $700-800 \mathrm{~km}$ with orbital periods of $\sim 100 \mathrm{~min}$. In both cases (GEO/LEO satellites), a constellation of satellites is required to provide adequate global coverage. This is achieved by current operational meteorological satellite constellations (Thépaut and Andersson 2010).

Satellite observations (LEO and GEO) and in situ observations (e.g., ground-based from surface networks) for AQ monitoring are complementary. In particular, satellite observations rely on ground-based observations for calibration and validation (USGEO 2010). In operational meteorology, data assimilation is used to combine the high accuracy of in situ observations with the high spatial coverage of satellite platforms (Andersson and Thépaut 2010). The relative merit of surface networks and satellite platforms (and their impact on the GOS versus cost), as well as the combination of in situ and satellite observations

FIG. 2. Map of $\mathrm{O}_{3}$ partial column (calculated over the height range $0-3 \mathrm{~km}$; height above the model surface) over Europe ( $x$ axis: longitude; $y$ axis: latitude) for I200 UTC (daytime) I Jul 2009; units are $10^{17}$ molecules $\mathrm{cm}^{-2}$. Red to purple colors denote the relatively high values of the $\mathrm{O}_{3}$ partial column, indicative of high levels of pollution and a need to monitor AQ; Blue colors denote relatively low values of $\mathrm{O}_{3}$ partial column. Note the relatively high values over the Po Valley in northern Italy and the Mediterranean and relatively low values over the Alps immediately to the north of the Po Valley. The influence of transport processes on tropospheric $\mathrm{O}_{3}$ concentrations over southern Europe and the Mediterranean has

been reviewed by Cristofanelli and Bonasoni (2009). Map is derived from a state-of-the-art CTM (MOCAGE; Bousserez et al. 2007). It shows high spatial variability over local scales in the lowermost troposphere, including the area near the ground (where human activity is of dominant influence). 
for AQ monitoring, is being studied in the POGEQA project using the notion of OSSEs (Masutani et al. 2010a,b). Claeyman et al. (2011a,b) describe initial efforts toward this goal.

A recent WMO gap analysis of space missions with respect to GCOS requirements (WMO 2011) discusses future plans for various tropospheric species that are relevant for $\mathrm{AQ}$. The main conclusion is that for $\mathrm{O}_{3}$, $\mathrm{CO}, \mathrm{NO}_{2}, \mathrm{SO}_{2}$, and $\mathrm{HCHO}$ long-term continuation of the observational record seems secured, in particular, from the LEO Sentinel-5 and post-EPS platforms. Plans for future operational satellites, although not optimal, are increasingly taking account of the need to measure aerosol properties (aerosol optical depth, concentration, effective radius, and type).

The twenty-first century is expected to see societal challenges that affect AQ: population growth, climate change, increased resource demand, and continual development of coastal and urban areas. Monitoring, forecasting, and managing AQ in the twenty-first century requires information about the Earth system and how it changes over time. This requires implementation and maintenance of a robust
GOS (USGEO 2010). Additional satellite observations (GEO and LEO) are needed to complement, extend, and fill gaps in the current GOS for $\mathrm{AQ}$, in particular, high spatiotemporal, height-resolved, continentalscale data on pollutants in the PBL and lowermost free troposphere. Additions to the GOS provide further observational data to constrain AQ forecast models with data assimilation/inverse modeling methods (Lahoz et al. 2010; Elbern et al. 2010). This constraint brings model improvement and increased understanding of processes affecting AQ. Users of these additional satellite data and their derived products include decision makers (e.g., the EC), local and national governments, pollution authorities, health authorities, industry, agriculture, and meteorological agencies. The main benefit is improved monitoring, forecasting, and management of AQ. The main beneficiary is human society.

\section{THE CASE FOR THE GEOSTATIONARY PLATFORM OVER A LOW EARTH ORBIT}

PLATFORM. Low Earth orbit satellites observe partial or full columns of several species relevant to AQ

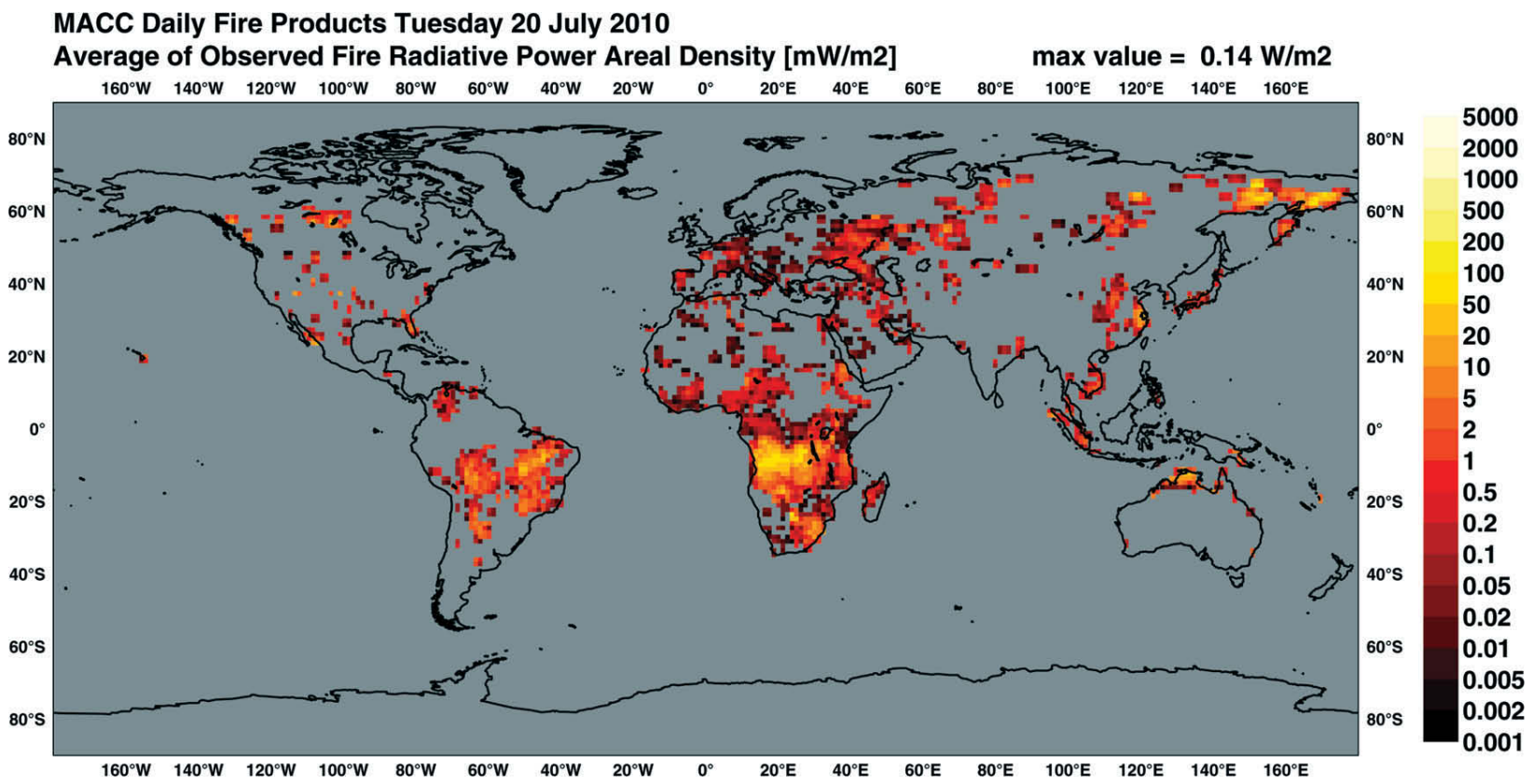

FIG. 3. Global map of average observed FRP areal density on $20 \mathrm{Jul} 2010$. It represents the thermal radiation measured from spaceborne sensors and detected as coming from actively burning vegetation and other open fires. It is expressed as the daily average of the FRP observations made in $125-\mathrm{km}$ grid cells and expressed in units of $\mathrm{mW} \mathrm{m}^{-2}$. The rate of release of thermal radiation by a fire is understood to be related to the rate at which fuel is being consumed and smoke produced. Daily-averaged FRP areal intensity data are used in the global estimation of open vegetation fire trace gas and particulate emissions. The map shows the spatial variability of fires over local scales; fires are a source of $\mathrm{CO}, \mathrm{NO}_{x}$, and aerosols (Andreae and Merlet 200I; GEO-CAPE 2008). Carbon monoxide is a proxy for pollutant transport; $\mathrm{NO}_{x}$ is a precursor for $\mathrm{O}_{3} ; \mathrm{O}_{3}$ and aerosols affect human health adversely, and their concentrations help define AQ. The map is a MACC Daily Fire Product (from www.gmes-atmosphere.eu/about/project_structure/input_data/d_fire/; see also Heil et al. 2010). 

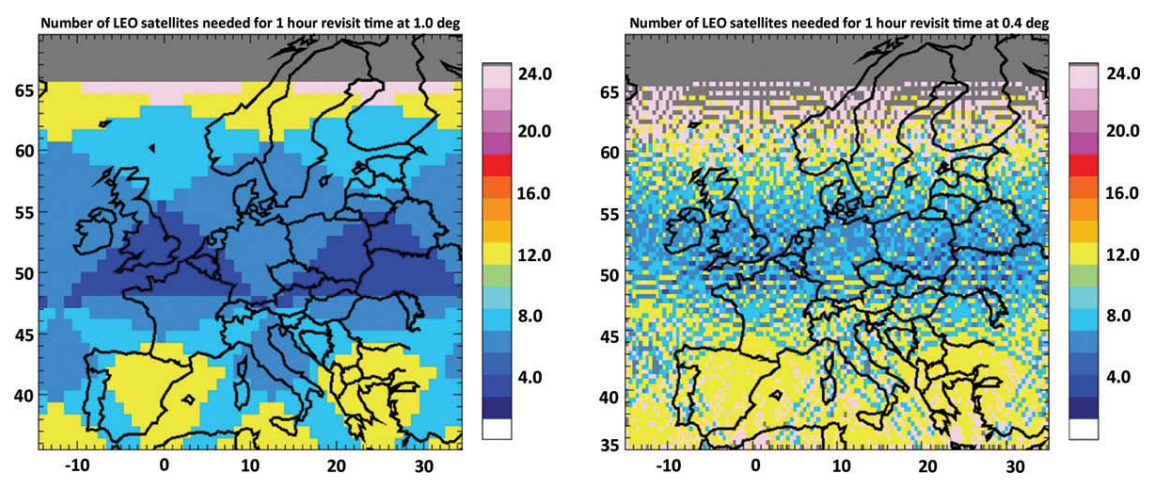

FIG. 4. The number of LEO satellites required for I-h revisit time over Europe. (left) $1^{\circ} \times 1^{\circ}$ resolution $(\sim 100 \mathrm{~km})$ and (right) $0.4^{\circ} \times 0.4^{\circ}$ resolution $(\sim 40 \mathrm{~km})$. Gray indicates no measurements are possible. In both cases, the least number of LEO satellites required is three (dark blue regions), but this is only for very small regions over Europe. For I-h revisit time and $\sim 10-\mathrm{km}$ (or less) resolution, the least number of LEO satellites required to cover Europe up to $60^{\circ} \mathrm{N}$ is more than 10; by contrast, only one GEO satellite is required. of pollutants or proxies for pollutants. Realistically (given technical, scientific, and cost considerations), a GEO satellite is the only satellite platform that can provide this information at the spatiotemporal scales that are associated with variability of tropospheric pollutants (temporal frequencies less than $1 \mathrm{~h}$; spatial scales less than $\sim 10 \mathrm{~km}$ ). A single GEO satellite provides $A Q$ information with complete temporal coverage over a key continental area of the globe (e.g.,
$\left(\mathrm{O}_{3}, \mathrm{CO}, \mathrm{NO}_{2}, \mathrm{HCHO}\right.$, and $\left.\mathrm{SO}_{2}\right)$ and make important contributions to pollution sources, transport, and characterization of air pollution variability at global, continental, and regional scales (NRC 2008). The last decade has seen major advances in observations of tropospheric species from LEO satellites (Fishman et al. 2008).

Low Earth orbit satellites provide a long-term global view of atmospheric composition, but they have limitations with respect to sampling atmospheric constituents in the lower troposphere at the spatiotemporal resolution necessary to monitor AQ. Their main advantage concerning AQ is their global coverage (this is possible from a single LEO satellite), typically covering most of the Earth, including regions close to the poles (in contrast, GEO satellites are limited to about a quarter of Earth's surface, and do not normally make observations poleward of $60^{\circ} \mathrm{N}$ or $60^{\circ} \mathrm{S}$ ). Thus, the main drawback for LEO satellites is the difficulty of achieving full temporal coverage, because for this purpose a constellation of more than 10 LEO satellites is required to give long-term hourly coverage at continental scales (Fig. 4).

A GEO platform has much better sampling of diurnal variability than a LEO platform (Fig. 4), and an improved likelihood of cloud-free observations (this, however, depends on pixel size) with continuous observations of a particular location during at least part of the day. This "stare" capability from a GEO provides significantly greater measurement integration times compared to those from a LEO satellite. This feature of the GEO satellite platform makes it very effective for the retrieval of the lowermost troposphere information for capturing the diurnal cycle in pollutants and emissions, and the import/export
Europe, East Asia, or North America), whereas many LEO satellites would be required to provide the same information (Fig. 4).

As of 2011, no observations of trace gases have been made from a GEO satellite. By contrast, multichannel imagers providing information on aerosols and fire-related parameters at high spatiotemporal resolution have been flying on NWP satellites in geostationary orbit for the past three decades (e.g., NOAA GOES series and the EUMETSAT Meteosat series). Both qualitative (smoke plume analysis and a dust mask) and quantitative (aerosol optical depth, main fire hot spots, and the size of unexpected fires and burned area) AQ products are currently available from GEO satellites.

To address shortcomings in the GOS, a number of initiatives in Europe are planning GEO satellites capable of monitoring chemical species. The GMES Sentinel-4 UVN platform (ESA 2007) will measure tropospheric $\mathrm{O}_{3}, \mathrm{NO}_{2}, \mathrm{HCHO}, \mathrm{SO}_{2}$, and aerosol properties (column-averaged optical thickness and aerosol type). The MTG IRS platform (Munro 2011) will measure tropospheric $\mathrm{O}_{3}$ and $\mathrm{CO}$ (although as a NWP sounder, it is not optimized for these species). Sentinel-4 UVN and MTG IRS instruments are due for launch from 2017/18 onward. The POGEQA and MAGEAQ initiatives (Peuch et al. 2009, 2010) focus on tropospheric $\mathrm{O}_{3}$ and $\mathrm{CO}$. The general concept behind these initiatives is discussed in Claeyman et al. (2011a,b).

A number of projects outside Europe are developing GEO satellites for monitoring chemical species. These include the NASA GEO-CAPE mission, with a proposed 2020 launch (GEO-CAPE 2008), the Korea MPGEOSAT mission, with a planned launch in 2017/18 
(Lee et al. 2010), and the JAXA AQ-Climate mission, with a 2020 proposed launch [Akimoto et al. 2008; see www.stelab.nagoya-u.ac.jp/ste-wwwl/divl/taikiken /eisei/eisei2.pdf (in Japanese)]. These developments in Europe, the United States, and Asia focus on tropospheric aerosols and trace gases such as $\mathrm{O}_{3}$. Synergies between European, the United States, and Asian GEO satellite platforms would be of great benefit for the quasi-global monitoring of AQ (CEOS 2011). Synergy between GEO and LEO satellite platforms and surface observations would provide further benefits.

\section{ACCOMPLISHMENTS OF SATELLITE PLAT- FORMS AND TECHNICAL DIFFICULTIES ASSOCIATED WITH GEOSTATIONARY MEASUREMENTS. To extract tropospheric infor-} mation from GEO and LEO platforms, it is necessary to separate stratospheric and tropospheric contributions to the signal received by the satellite. Commonly, this is achieved by taking advantage of the different penetration depths into the atmosphere of different spectral regions (UV, VIS, TIR, and NIR).

This approach has been used to measure tropospheric trace gases and aerosols from LEO platforms in the UV, VIS, and infrared (Fishman et al. 2008). For the UV/VIS these include 1) a tropospheric $\mathrm{O}_{3}$ column from GOME with mean biases of up to $3 \mathrm{DU}$ and standard deviations within 3-8 DU against ozonesondes (Liu et al. 2005); 2) $\mathrm{O}_{3}$ profiles from OMI with tropospheric information of up to $1.5 \mathrm{DFS}^{4}$, peaking between 500 and $700 \mathrm{hPa}$ and sensitivity down to $\sim 800-900 \mathrm{hPa}$, and random errors of $\sim 10 \%$ (Liu et al. 2010); 3) tropospheric columns of $\mathrm{NO}_{2}, \mathrm{SO}_{2}, \mathrm{HCHO}$, and $\mathrm{C}_{2} \mathrm{H}_{2} \mathrm{O}_{2}$ from GOME and/or SCIAMACHY (Chance 2005, 2006, and references therein); and
4) aerosol products from biomass burning: aerosol optical depth from MODIS and aerosol absorption optical depth and UV aerosol index from OMI (Torres et al. 2010). For the infrared these include 1) lowertroposphere (between the surface and $700 \mathrm{hPa}$ ) CO profile retrievals from MOPITT (Deeter et al. 2007); 2) near-surface (from the surface to $800 \mathrm{hPa}$ ) increased CO information (quantified by the DFS) from TIR + NIR MOPITT retrievals in comparison to TIR-only MOPITT retrievals (Worden et al. 2010); 3) the partial $\mathrm{O}_{3}$ column $(0-6 \mathrm{~km})$ and tropospheric $\mathrm{O}_{3}$ column $(0-11 \mathrm{~km})$ from IASI, with a bias of $5 \%$ or less against ozonesondes (Eremenko et al. 2008; Keim et al. 2009); and 4) a capability for height-resolved tropospheric $\mathrm{O}_{3}$ information (DFS of 2.4) from TES and a demonstration of sensitivity to $\mathrm{CO}$ concentrations between 5 and $15 \mathrm{~km}$ from TES (Worden et al. 2004). As part of this effort, ESA missions have been instrumental in building a picture of pollution over various regions of the globe (Fig. 5).

The ability to retrieve trace gas concentrations in the PBL is important for the characterization of pollutant sources. In addition to source determination, a measure of PBL concentration in conjunction with free troposphere profile information allows local production to be separated from transported pollution. However, these retrievals are challenging for both LEO and GEO platforms. Spectral signatures from the UV to NIR are subject to interferences from clouds, aerosols, scattering, and surface reflectivity uncertainties. In the TIR, the general lack of temperature contrast between the atmosphere and surface limits PBL retrieval capability (Orphal et al. 2005). For $\mathrm{O}_{3}$, because the tropospheric column accounts for less than $10 \%$ of the total column, it is challenging to

${ }^{4}$ The DFS quantify the number of useful independent quantities in the measurement (Rodgers 2000).

SCIAMACHY tropospheric $\mathrm{NO}_{2}-2009$
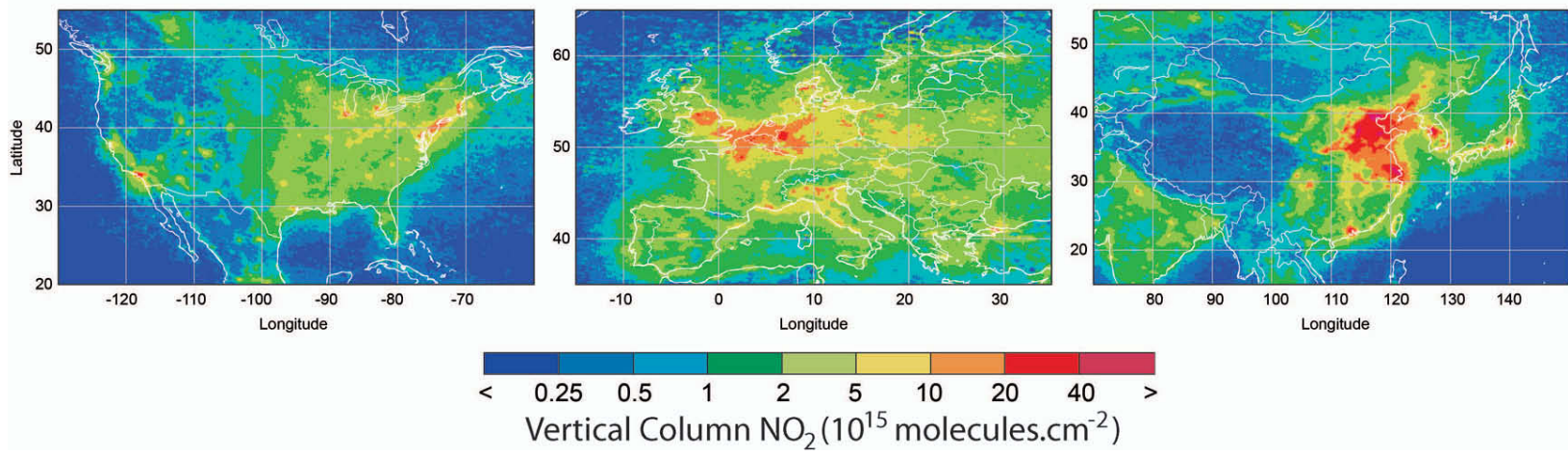

FIG. 5. NO tropospheric densities (representative of the vertical column), averaged for 2009 , from the SCIAMACHY instrument on board the ESA Envisat satellite. (left) United States, (middle) Europe, and (right) China. Units are $10^{15}$ molecules $\mathrm{cm}^{-2}$. [Figure courtesy A. Richter (IUP-IFE, University of Bremen).] 
separate $\mathrm{PBL} \mathrm{O}_{3}$ from stratospheric $\mathrm{O}_{3}$, even for LEO satellites (Fishman et al. 2008).

Notwithstanding these challenges, studies show the potential of multispectral observations to extract $\mathrm{PBL}$ information, with $\mathrm{O}_{3}$ and $\mathrm{CO}$ being the best candidate species at present. Retrieval studies for combining OMI and TES $\mathrm{O}_{3}$ measurements (Landgraf and Hasekamp 2007; Worden et al. 2007) indicate that such combinations are highly promising. This approach requires measurements from at least two $\mathrm{O}_{3}$ bands from among the ultraviolet Hartley-Huggins (200-360 nm), the visible Chappuis $(375-650 \mathrm{~nm})$, and the thermal infrared $v_{3}$ band $(9.6 \mu \mathrm{m})$.

The combination of TIR + VIS (combinations such as UV + VIS, TIR + UV, and TIR + UV + VIS are also being considered) measurements for $\mathrm{O}_{3}$ (in a LEO or GEO platform) is desirable because, for clear skies, the visible Chappuis bands view directly to the ground, overcoming the difficulties from $\mathrm{UV} \mathrm{O}_{3}$ measurements (which are limited in near-surface sensitivity by Rayleigh scattering) and infrared $\mathrm{O}_{3}$ measurements (limited by low thermal contrast between the Earth's surface and the lower atmosphere; note that the VIS and UV do not provide information at night). However, the absorption in the Chappuis band is weak, and the potential aerosol contamination of species retrievals and variations in the surface reflectance as a function of wavelength may present challenges.

Measurement of $\mathrm{PBL} \mathrm{O}_{3}$ concentrations to desired precision levels is the major current technical difficulty for GEO platforms. The major missing components of tropospheric $\mathrm{O}_{3}$ measurements are 1) the ability to make precise $\mathrm{O}_{3}$ measurements from the nadir (downward looking) geometry using the visible Chappuis band, as has been used for SAGE-II and other measurements of $\mathrm{O}_{3}$ in solar occultation geometry (e.g., McCormick et al. 1989); and 2) the capability to perform multispectral retrievals, which improves the sensitivity to different atmospheric altitudes (Fig. 6). Studies on the feasibility of the multispectral approach to make $\mathrm{O}_{3}$ measurements in the PBL from a GEO platform are being performed for GEO-CAPE (Natraj et al. 2011), and will be undertaken for the POGEQA project (Claeyman et al. 2011b). OSSEs will be a key tool in these studies.

Regarding $\mathrm{CO}$ measurements in the PBL from a GEO platform, these observations will require a multispectral TIR + NIR retrieval (GEO-CAPE 2008). Regarding tropospheric aerosol measurements, multiangle observations over the course of a day from a GEO platform are expected to provide information on aerosol properties such as aerosol optical depth (Zhang et al. 2011). The proposed GEO-CAPE spectral coverage in the UV/VIS is expected to provide the capability to simultaneously measure aerosol optical depth, size distribution, and aerosol absorption (GEO-CAPE 2008). Availability of UV channels in the GEO-CAPE mission are expected to allow identification and characterization of organic aerosols that have a unique spectral signature in the UV but
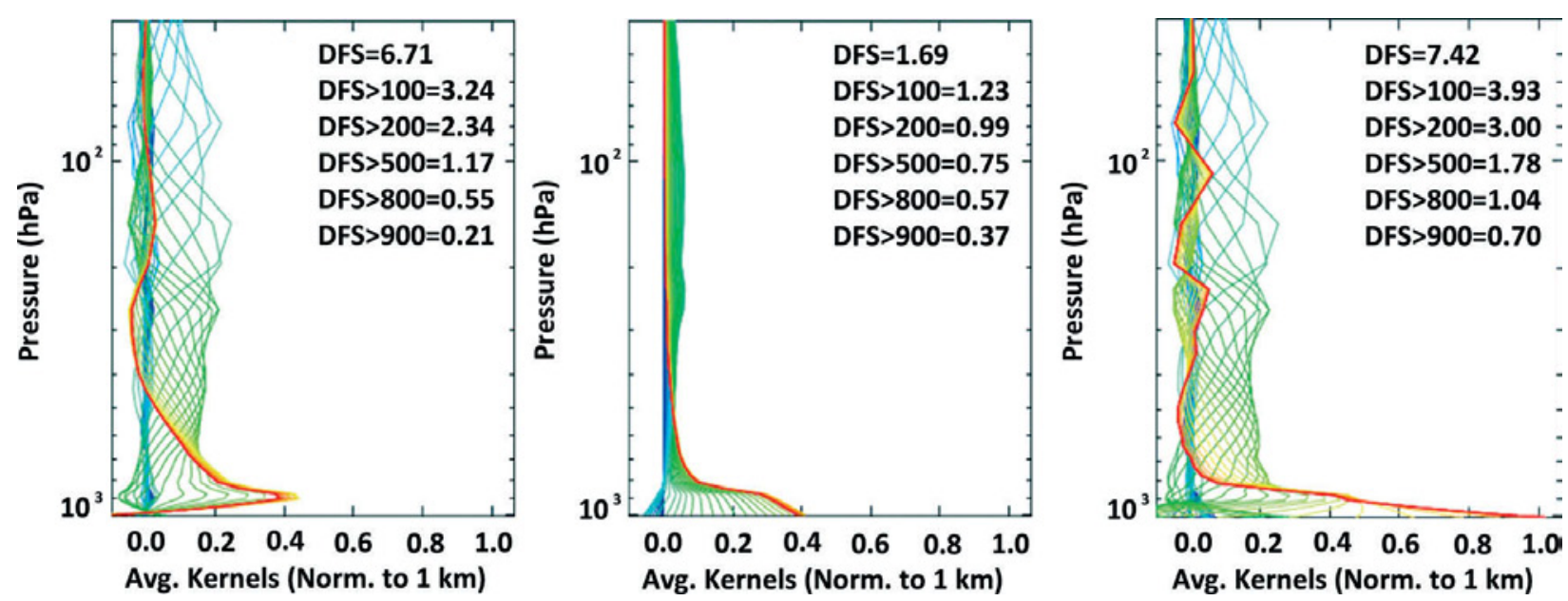

FIG. 6. Representative $\mathrm{O}_{3}$ averaging kernels (normalized to I km; green and red) for 6-nm sampling. (Left) TIR, (middle) VIS, and (right) TIR + VIS. Averaging kernels relate the sensitivity of the retrieval to the true state (Rodgers 2000), and here identify the location in the vertical where measurements have information. This figure shows the TIR + VIS multispectral retrieval improves on individual TIR and VIS retrievals in the lowermost troposphere. Improvement is quantified by an increase in the DFS: I) pressures greater than $800 \mathrm{hPa}$ are 1.04 for TIR + VIS versus 0.55 for TIR and 0.57 for VIS; and 2) pressures greater than $900 \mathrm{hPa}$ are 0.70 for TIR + VIS versus $\mathbf{0 . 2 I}$ for TIR and 0.37 for VIS. Multispectral retrievals are being studied by Natraj et al. (20II). 
are not easy to differentiate from other aerosol types with visible-only observations.

Despite the advantages for monitoring the AQ of a GEO satellite compared to a LEO satellite, a GEO satellite will significantly lose signal and spatial resolution owing to its longer distance from the Earth (compared to a LEO satellite). Thus, a GEO platform will be challenged by data accuracy and spatial resolution. This requires the use of larger telescopes by a GEO satellite. However, the continued observation of a given area by a single pixel by a GEO satellite allows the integration of signals to recover a satisfactory signal-to-noise ratio while still achieving a high temporal resolution (less than $1 \mathrm{~h}$ ) and providing an improved likelihood of cloud-free observations (this, however, depends on pixel size).

Regardless of the eventual instrumentation in GEO platforms to provide the required spatiotemporal information of tropospheric trace gases and aerosols, a substantial challenge is the development of modeling and data assimilation tools to use this information. Work on developing these tools has already started (Lahoz et al. 2010; Elbern et al. 2010), and their application to the study of tropospheric species that define AQ will play a crucial role in the development of a robust capability to monitor, forecast, and manage AQ.

SUMMARY. The importance of taking action on $\mathrm{AQ}$ and the need for abatement technologies has led to a strong societal response based on monitoring surface concentrations of key pollutants and scientific understanding of their impact. This requires the ability to observe the lowermost troposphere at regional and continental scales at high spatiotemporal resolution. A geostationary platform is the only realistic space-based solution (given technical, scientific, and cost considerations) providing this information from space, but important technical difficulties concerning instrument design must be overcome. This paper outlines how the potential of a geostationary platform for AQ monitoring can be achieved. A key part of this effort will be the use of satellite and in situ data to constrain AQ forecast models with data assimilation/inverse modeling methods. This will bring model improvement and increased understanding of processes affecting AQ. Geostationary platforms will improve our ability to monitor, forecast, and manage $A Q$, benefitting human society. Current plans for the future GOS lack the constellation of dedicated GEO missions needed for monitoring AQ over Europe, North America, and Asia; this shortcoming should be remedied.
ACKNOWLEDGMENTS. This work was funded by the Centre National de la Recherche Scientifique (CNRS), EADS-ASTRIUM, the Centre National de Recherches Météorologiques (CNRM) of Météo-France, the RTRA/ STAE (project POGEQA), and the INFOAIR project funded by Région Midi-Pyrénées. Work at NILU was funded by an internal project. Research at the Harvard-Smithsonian Center for Astrophysics was funded by NASA and the Smithsonian Institution. Work at Karlsruhe Institute of Technology was funded by the Helmholtz Association of German Research Centres. Work at the National Center for Atmospheric Research (NCAR) was funded by NASA. Thanks to Finn Bjørklid (NILU) and Matthieu Joly (CNRM) for helping with figures. We thank the reviewers and the editor for making suggestions that helped improve the paper.

\section{REFERENCES}

AFSSET, 2007: Impacts économiques des pathologies liées à la pollution. Étude d'Impact sur les Coûts que Représentent pour l'Assurance Maladie Certaines Pathologies Liées à la Pollution, AFSSET Rep., 139 pp. [Available online at www.afssa.fr/ET/DocumentsET /couts_assurance_maladie_pathologies_pollution .pdf.]

Akimoto, H., 2003: Global air quality and climate. Science, 302, 1716-1719.

—, H. Irie, Y. Kasai, K. Kita, M. Koike, Y. Kondo, T. Nakazawa, and S. Hayashida, 2008: Planning a geostationary atmospheric observation satellite. Commission on the Atmospheric Observation Satellite of the Japan Society of Atmospheric Chemistry, Atmospheric Composition Research Program, Frontier Research Center for Global Change, JAMSTEC.

Andersson, E., and J.-N. Thépaut, 2010: Assimilation of operational data. Data Assimilation: Making Sense of Observations, W. A. Lahoz, B. Khattatov, and R. Ménard, Eds., Springer, 283-299.

Andreae, M. O., and P. Merlet, 2001: Emission of trace gases and aerosols from biomass burning. Global Biogeochem. Cycles, 15, 955-966.

Aneja, V. P., W. H. Schlesinger, and J. W. Erisman, 2008: Farming pollution. Nat. Geosci., 1, 409-411.

Bousserez, N., and Coauthors, 2007: Evaluation of MOCAGE chemistry transport model during the ICARTT/ITOP experiment. J. Geophys. Res., 112, D10S42, doi:10.1029/2006JD007595.

Brasseur, G. P., R. G. Prinn, and Alexander A. P. Pszenny, Eds., 2003: Atmospheric Chemistry in a Changing World. Springer-Verlag, $300 \mathrm{pp}$.

Brunekreef, B., and S. T. Holgate, 2002: Air pollution and health. Lancet, 360, 1233-1242. 
CEOS, 2011: A geostationary satellite constellation for observing global air quality: An international path forward. CEOS Atmospheric Composition Constellation, version 4, $41 \mathrm{pp}$. [Available online at www .ceos.org/images/ACC/AC_Geo_Position_Paper_ v4.pdf.]

Chance, K., 2005: Ultraviolet and visible spectroscopy and spaceborne remote sensing of the earth's atmosphere. C. R. Phys., 6, 836-847.

_ 2006: Spectroscopic measurements of tropospheric composition from satellite measurements in the ultraviolet and visible: Steps toward continuous pollution monitoring from space. Remote Sensing of the Atmosphere for Environmental Security, A. Perrin, N. Ben Sari-Zizi, and J. Demaison, Eds., NATO Security through Science Series, Vol. XI, Springer, 1-25.

Claeyman, M., and Coauthors, 2011a: A geostationary thermal infrared sensor to monitor the lowermost troposphere: $\mathrm{O}_{3}$ and $\mathrm{CO}$ retrieval studies. Atmos. Meas. Tech., 4, 297-317.

— , and Coauthors, 2011b: A thermal infrared instrument onboard a geostationary platform for $\mathrm{CO}$ and $\mathrm{O}_{3}$ measurements in the lowermost troposphere: Observing system simulation experiments. Atmos. Meas. Tech., 4, 1637-1661.

Cooper, O. R., and Coauthors, 2010: Increasing springtime ozone mixing ratios in the free troposphere over western North America. Nature, 463, 344-348.

Cristofanelli, P., and P. Bonasoni, 2009: Background ozone and the Mediterranean area: Influence of the transport processes. Environ. Pollut., 157, 1399-1406.

Crutzen, P. J., 1974: Photochemical reactions initiated by and influencing ozone in unpolluted tropospheric air. Tellus, 26, 46-57.

Deeter, M. N., D. P. Edwards, J. C. Gille, and J. R. Drummond, 2007: Sensitivity of MOPITT to carbon monoxide in the lower troposphere. J. Geophys. Res., 112, D24306, doi:10.1029/2007JD008929.

Dentener, F., and Coauthors, 2006: The global atmospheric environment for the next generation. Environ. Sci. Technol., 40, 3586-3594.

Deutsche Umwelthilfe, 2005: Impacts of air pollution on human health. Deutsche Umwelthife Document, 5 pp. [Available online at www.duh .de/uploads/media/EU_2005__02.doc.]

Dominici, F., R. D. Peng, C. D. Barr, and M. L. Bell, 2010: Protecting human health from pollution: Shifting from a single-pollutant to a multi-pollutant approach. Epidemiology, 21, 187-194.

Elbern, H., A. Strunk, and L. Nieradzik, 2010: Inverse modelling and combined state-source estimation for chemical weather. Data Assimilation: Making Sense of Observations, W. A. Lahoz, B. Khattatov, and R. Ménard, Eds., Springer, 491-515.

Eremenko, M., G. Dufour, G. Foret, C. Keim, J. Orphal, M. Beekmann, G. Bergametti, and J.-M. Flaud, 2008: Tropospheric ozone distributions over Europe during the heat wave in July 2007 observed from infrared nadir spectra measured by IASI. Geophys. Res. Lett., 35, L18805, doi:10.1029/2008GL034803.

ESA, 2007: GMES sentinels 4 and 5. Mission Requirements Document EOP-SMA/1507, 87 pp.

Fishman, J., and Coauthors, 2008: Remote sensing of tropospheric pollution from space. Bull. Amer. Meteor. Soc., 89, 805-821.

GEO-CAPE, 2008: Geostationary Coastal and Air Pollution Events. GEO-CAPE Mission NASA Workshop Rep., 50 pp. [Available online at http://geo-cape.larc .nasa.gov/docs/GEO-CAPE_Wkshp_RPt_Final-all .pdf.]

Hegglin, M. I., and T. G. Shepherd, 2009: Large climate-induced changes in ultraviolet index and stratosphere-to-troposphere ozone flux. Nat. Geosci., 2, 687-691, doi:10.1038/ngeo604.

Heil, A., J. W. Kaiser, G. R. van der Werf, M. J. Wooster, M. G. Schultz, and H. Dernier van der Gon, 2010: Assessment of the real-time fire emissions (GFASv0) by MACC. ECMWF Tech. Memo. 628, 43 pp. [Available online at www.ecmwf.int.]

Hollingsworth, A., and Coauthors, 2008: Towards a monitoring and forecasting system for atmospheric composition: The GEMS Project. Bull. Amer. Meteor. Soc., 89, 1147-1164.

IGACO, 2004: The changing atmosphere: An Integrated Global Atmospheric Chemistry Observation theme for the IGOS partnership. ESA SP-1282, GAW Rep. 159, WMO/TD-1235, 72 pp. [Available online at ftp://ftp.wmo.int/Documents/PublicWeb/arep/gaw /gaw159.pdf.]

Keim, C., and Coauthors, 2009: Tropospheric ozone from IASI: Comparison of different inversion algorithms and validation with ozone sondes in the northern middle latitudes. Atmos. Chem. Phys., 9, 9329-9347.

Lahoz, W. A., B. Khattatov, and R. Ménard, 2010: Data assimilation and information. Data Assimilation: Making Sense of Observations, W. A. Lahoz, B. Khattatov, and R. Ménard, Eds., Springer, 3-12.

Landgraf, J., and O. Hasekamp, 2007: Retrieval of tropospheric ozone: The synergistic use of thermal infrared emission and ultraviolet reflectivity measurements from space. J. Geophys. Res., 112, D08310, doi:10.1029/2006JD008097.

Lawrence, M. G., and J. Lelieveld, 2010: Atmospheric pollutant outflow from southern Asia: A review. Atmos. Chem. Phys., 10, 11 017-11 096. 
Lee, S., Y. Hong, C.-K. Song, J. Lee, W.-J. Choi, D. Kim, K.-J. Moon, and J. Kim, 2010: Plan of Korean geostationary environment satellite over Asia-Pacific region. Geophysical Research Abstracts, Abstract EGU-20107595-1. [Available online at http://meetingorganizer .copernicus.org/EGU2010/EGU2010-7595-1.pdf.]

Lin, M., T. Holloway, G. R. Carmichael, and A. M. Fiore, 2010: Quantifying pollution inflow and outflow over East Asia in spring with regional and global models. Atmos. Chem. Phys., 10, 4221-4239.

Liu, X., K. Chance, C. E. Sioris, R. J. D. Spurr, T. P. Kurosu, R. V. Martin, and M. J. Newchurch, 2005: Ozone profile and tropospheric ozone retrievals from global ozone monitoring experiment: Algorithm description and validation. J. Geophys. Res., 110, D20307, doi:10.1029/2005JD006240.

—, P. K. Bhartia, K. Chance, R. J. D. Spurr, and T. P. Kurosu, 2010: Ozone profile retrievals from the ozone monitoring instrument. Atmos. Chem. Phys., 10, 2521-2537.

Lucas, A., and Coauthors, 2010: Carbon monoxide pollution promotes cardiac remodeling and ventricular arrhythmia in healthy rats. Amer. J. Respir. Crit. Care Med., 181, 587-595.

Masutani, M., and Coauthors, 2010a: Observing system simulation experiments at the National Centers for Environmental Prediction. J. Geophys. Res., 115, D07101, doi:10.1029/2009JD012528.

— - and Coauthors, 2010b: Observing system simulation experiments. Data Assimilation: Making Sense of Observations, W. A. Lahoz, B. Khattatov, and R. Ménard, Eds., Springer, 647-679.

McCormick, M. P., J. M. Zawodny, R. E. Veiga, J. C. Larsen, and P. H. Wang, 1989: An overview of SAGE I and II ozone measurements. Planet. Space Sci., 37, 1567-1586.

McNair, L. A., R. A. Hartley, and A. G. Russell, 1996: Spatial inhomogeneity in pollution concentrations and their implications for air quality model evaluation. Atmos. Environ., 39, 4291-4301.

Meyer, G., and Coauthors, 2010: Simulated urban carbon monoxide air pollution exacerbates rat heart ischemia-reperfusion injury. Amer. J. Physiol. Heart Circ. Physiol., 298, H1445-H1453.

Molina, M. J., and L. T. Molina, 2004: Megacities and atmospheric pollution. J. Air Waste Manage. Assoc., 54, 644-680.

Munro, R., cited 2011: Future EUMETSAT satellite missions. [Available online at http://earth.eo.int /workshops/Volcano/files/EUMETSAT_Future Missions_Rose_Munro.pdf.]

Natraj, V., and Coauthors, 2011: Multi-spectral sensitivity studies for the retrieval of tropospheric and lowermost tropospheric ozone from simulated clearsky GEO-CAPE measurements. Atmos. Environ., 45, 7151-7165.

NRC, 2008: Earth Observations from Space: The First 50 Years of Scientific Achievements. National Academies Press, 129 pp.

Orphal, J., G. Bergametti, B. Beghin, J.-P. Hébert, T. Steck, and J.-M. Flaud, 2005: Monitoring tropospheric pollution using infrared spectroscopy from geostationary orbit. C. R. Phys., 6, 888-896.

Peuch, V.-H., and Coauthors, 2009: Data assimilation experiments within the POGEQA project. Eos, Trans. Amer. Geophys. Union, 90 (Fall Meeting Suppl.), Abstract A51M-05.

— , and Coauthors, 2010: MAGEAQ: Monitoring the Atmosphere from Geostationary Orbit for European Air Quality. Earth Explorer Opportunity Mission Ee-8 Proposal, ESA, 185 pp.

Pope, C. A., III, M. Ezzati, and D. W. Dockery, 2009: Fine-particulate air pollution and life expectancy in the United States. N. Engl. J. Med., 360, 376-386.

Prather, M., and Coauthors, 2003: Fresh air in the 21 st century? Geophys. Res. Lett., 30, 1100, doi:10.1029/2002GL016285.

Rodgers, C. D., 2000: Inverse Methods for Atmospheric Sounding: Theory and Practice. World Scientific, $238 \mathrm{pp}$.

Rouil, L., and Coauthors, 2009: PREV'AIR: An operational forecasting and mapping system for air quality in Europe. Bull. Amer. Meteor. Soc., 90, 73-83.

Rypdal, K., N. Rive, T. Berntsen, H. Fagerli, Z. Klimont, T. K. Mideksa, and J. S. Fuglestvedt, 2009: Climate and air quality-driven scenarios of ozone and aerosol precursor abatement. Environ. Sci. Pol., 12, 855-869.

Solomon, S., and Coauthors, 2007: Technical summary. Climate Change 2007: The Physical Science Basis, S. Solomon et al., Eds., Cambridge University Press, $74 \mathrm{pp}$.

Thépaut, J.-N., and E. Andersson, 2010: The global observing system. Data Assimilation: Making Sense of Observations, W. A. Lahoz, B. Khattatov, and R. Ménard, Eds., Springer, 263-281.

Torres, O., Z. Chen, H. Jethva, C. Ahn, S. R. Freitas, and P. K. Bhartia, 2010: OMI and MODIS observations of the anomalous 2008-2009 Southern Hemisphere biomass burning seasons. Atmos. Chem. Phys., 10, 3505-3513.

USGEO, 2010: Achieving and sustaining earth observations: A preliminary plan based on a strategic assessment by the U.S. Group on Earth Observations. Office of Science and Technology Policy, 69 pp. [Available online at www.whitehouse.gov/sites 
/default/files/microsites/ostp/ostp-usgeo-reportearth-obs.pdf.]

Vautard, R., C. Honoré, M. Beekmann, and L. Rouill, 2005: Simulation of ozone during the August 2003 heat wave and emission control scenarios. Atmos. Environ., 39, 2957-2967.

Volkamer, R., L. T. Molina, M. J. Molina, T. Shirley, and W. H. Brune, 2005: DOAS measurement of glyoxal as an indicator for fast VOC chemistry in urban air. Geophys. Res. Lett., 32, L08806, doi:10.1029/2005GL022616.

Worden, H. M., M. N. Deeter, D. P. Edwards, J. C. Gille, J. R. Drummond, and P. Nédelec, 2010: Observations of near-surface carbon monoxide from space using MOPITT multispectral retrievals. J. Geophys. Res., 115, D18314, doi:10.1029/2010JD014242.

Worden, J., S. S. Kuwalik, M. W. Shephard, S. A. Clough, H. Worden, K. Bowman, and A. Goldman, 2004: Predicted errors of tropospheric emission spectrometer nadir retrievals from spectral window selection. J. Geophys. Res., 109, D09308, doi:10.1029/2004JD004522.

- , X. Liu, K. Bowman, K. Chance, R. Beer, A. Eldering, M. Gunson, and H. Worden, 2007: Improved tropospheric ozone profile retrievals using
OMI and TES radiances. Geophys. Res. Lett., 34, L01809, doi:10.1029/2006GL027806.

WHO, 2000: Air quality guidelines for Europe. 2nd ed. WHO Regional Publications, European Series, 91, 288 pp. [Available online at www.euro.who.int/__ data/assets/pdf_file/0005/74732/E71922.pdf.]

_- 2005: Ecosystems and human well-being: Health synthesis. Millennium Ecosystem Assessment, 64 pp. [Available online at www.who.int/globalchange /ecosystems/ecosys.pdf.]

_ 2011: WMO gap analysis of space missions with respect to GCOS requirements. Workshop on Continuity and Architecture Requirements for Climate Monitoring, Geneva, Switzerland, WMO, 80 pp. [Available online at www.wmo.int/pages/prog/sat/meetings /documents/ARCH-WK-1_Doc_03-02_ECV-gap -analysis.pdf.]

Zeng, G., O. Morgenstern, P. Braesicke, and J. A. Pyle, 2010: Impact of stratospheric ozone recovery on tropospheric ozone and its budget. Geophys. Res. Lett., 37, L09805, doi:10.1029/2010GL042812.

Zhang, H., A. Lyapustin, Y. Wang, S. Kondragunta, I. Laszlo, P. Ciren, and R. M. Hoff, 2011: A multiangle aerosol optical depth retrieval algorithm for geostationary satellite data over the United States. Atmos. Chem. Phys., 11, 11977-11991.

\author{
APPENDIX A: ACRONYMS USED IN THIS ARTICLE. \\ AQ \\ BDQA \\ $\mathrm{C}_{2} \mathrm{H}_{2} \mathrm{O}_{2}$ \\ CAFE \\ CEOS \\ $\mathrm{CO}$ \\ CTM \\ DFS \\ DU \\ EC \\ EMEP \\ EPA \\ EPS \\ ESA \\ EU \\ EUMETSAT \\ EU25 \\ FRP \\ GCOS \\ GEMS \\ GEO \\ GEO-CAPE \\ GMES \\ GOES \\ Air quality \\ Base d Données sur la Qualité de l'Air \\ Glyoxal \\ Clean Air for Europe \\ Committee on Earth Observation Satellites \\ Carbon monoxide \\ Chemistry transport model \\ Degrees of freedom for signal \\ Dobson unit \\ European Commission \\ European Monitoring and Evaluation Programme \\ Environmental Protection Agency \\ EUMETSAT Polar System \\ European Space Agency \\ European Union \\ European Organisation for the Exploitation of Meteorological Satellites \\ 25 members in the European Union \\ Fire radiative power \\ Global Climate Observing System \\ Global Earth System Monitoring Using Space and In Situ Data \\ Geostationary \\ Geostationary Coastal and Air Pollution Events \\ Global Monitoring for Environment and Security \\ Geostationary Operational Environmental Satellite
}




\begin{tabular}{|c|c|}
\hline GOME & Global Ozone Monitoring Experiment \\
\hline GOS & Global Observing System \\
\hline $\mathrm{HCHO}$ & Formaldehyde \\
\hline IASI & Infrared Atmospheric Sounding Interferometer \\
\hline IGACO & Integrated Global Atmospheric Chemistry Observations \\
\hline IPCC & Intergovernmental Panel on Climate Change \\
\hline JAXA & Japan Aerospace Space Exploration Agency \\
\hline LEO & Low Earth Orbit \\
\hline MACC & Monitoring Atmospheric Composition and Climate \\
\hline MAGEAQ & Monitoring the Atmosphere from Geostationary Orbit for European Air Quality \\
\hline MOCAGE & $\begin{array}{l}\text { Modélisation de Chimie Atmosphérique à Grande Echelle (Model of Atmospheric Chemistry } \\
\text { at Large Scales) }\end{array}$ \\
\hline MODIS & Moderate Resolution Imaging Spectroradiometer \\
\hline MOPITT & Measurements of Pollution in the Troposphere \\
\hline MP-GEOSAT & Multipurpose Geostationary Satellite \\
\hline MTG-IRS & Meteosat Third-Generation Infrared Sounder \\
\hline NASA & National Aeronautics and Space Administration \\
\hline NIR & Near infrared \\
\hline $\mathrm{NO}_{2}$ & Nitrogen dioxide \\
\hline $\mathrm{NO}_{\mathrm{x}}^{2}$ & Nitrogen oxide \\
\hline NOAA & National Oceanic and Atmospheric Administration \\
\hline $\mathrm{O}_{3}$ & Ozone \\
\hline $\mathrm{OH}$ & Hydroxyl radical \\
\hline OMI & Ozone Monitoring Instrument \\
\hline OSSE & Observing System Simulation Experiment \\
\hline $\mathrm{PM}$ & Particulate matter \\
\hline $\mathrm{PM}_{2,5}$ & Particulate matter integrated up to a diameter of $2.5 \mu \mathrm{m}$ \\
\hline POGEQA & $\begin{array}{l}\text { Plateforme d'Observation Geostationnaire pour la Mesure de la Qualité de l'Air } \\
\text { (Observation of air quality from a geostationary platform) }\end{array}$ \\
\hline ppbv & Parts per billion by volume \\
\hline SAGE & Stratospheric Aerosol and Gas Experiment \\
\hline SCIAMACHY & Scanning Imaging Absorption Spectrometer for Atmospheric Chartography \\
\hline SRES & Special Report on Emissions Scenarios \\
\hline TES & Tropospheric Emission Spectrometer \\
\hline TIR & Thermal infrared \\
\hline UVN & Ultraviolet-visible-near infrared \\
\hline VIS & Visible \\
\hline VOC & Volatile organic compound \\
\hline WHO & World Health Organization \\
\hline WMO & World Meteorological Organization \\
\hline
\end{tabular}




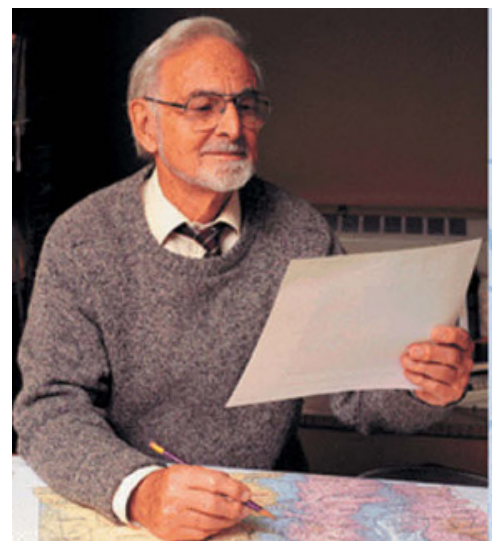

A Half Century of Progress in Meteorology:

A Tribute to Richard Reed

edited by Richard H. Johnson and Robert A. Houze Jr.

with selections by: Lance F. Bosart Robert W. Burpee Anthony Hollingsworth James R. Holton Brian J. Hoskins Richard S. Lindzen John S. Perry Erik A. Rasmussen Adrian Simmons Pedro Viterbo

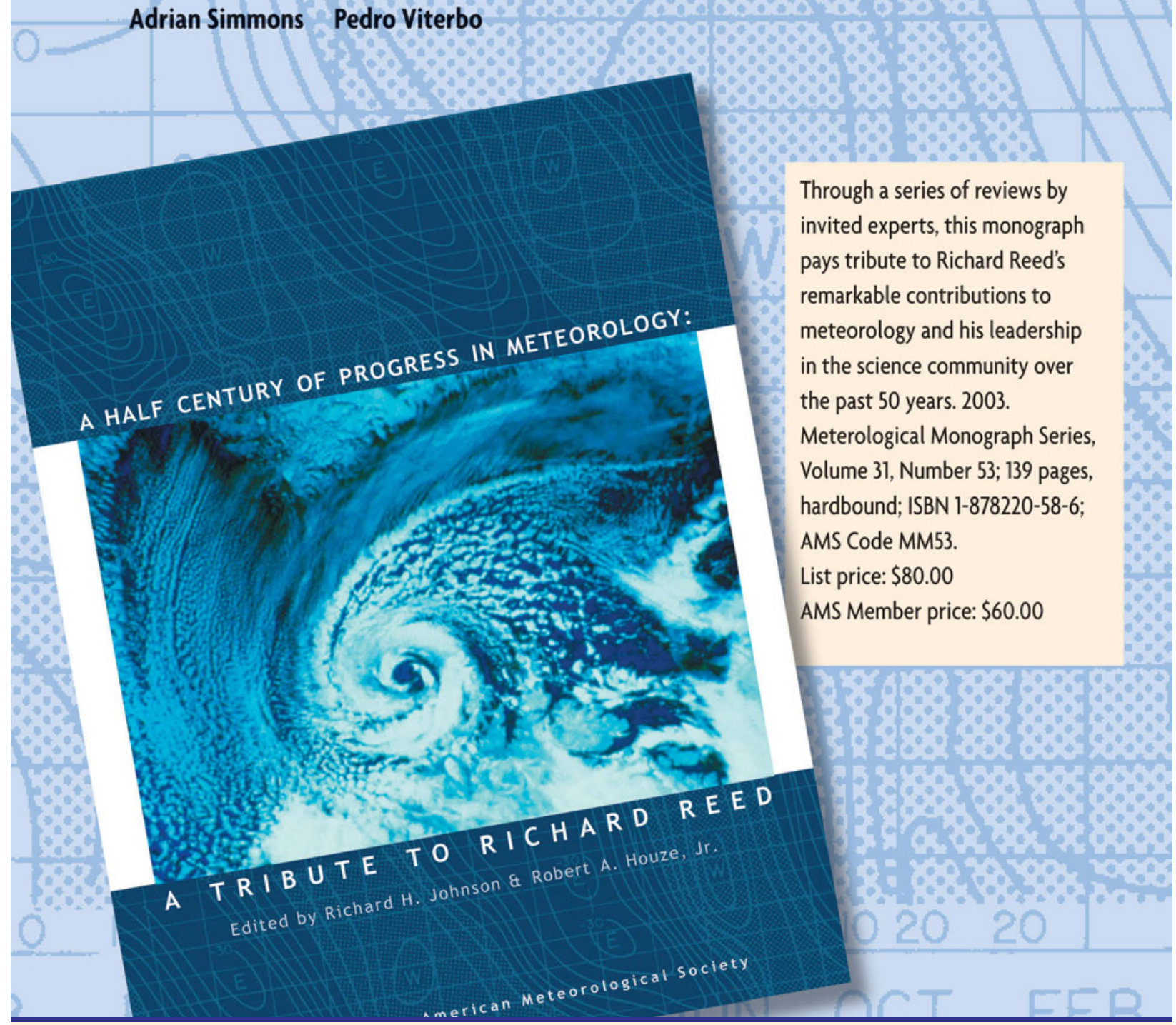

ORDER ONLINE: www.ametsoc.org/amsbookstore or see the order form at the back of this issue 